\title{
Students' Perceptions of Using a Novel as Main Material in the EFL Reading Course
}

\author{
Chih-hsin Tsai ${ }^{1}$ \\ ${ }^{1}$ Department of Applied English, Hungkuang University, Taiwan \\ Correspondence: Chih-hsin Tsai, Department of Applied English, Hungkuang University, No. 34, Chung-chi Rd., \\ Shalu, Taichung 43302, Taiwan R.O.C. Tel: 1-886-4-26318652. E-mail: chtsai@sunrise.hk.edu.tw
}

Received: March 25, 2012 Accepted: May 4, 2012 Online Published: July 3, 2012

doi:10.5539/elt.v5n8p103 URL: http://dx.doi.org/10.5539/elt.v5n8p103

\begin{abstract}
The study looked into the possibility of using a novel as main material in a college EFL reading course. It focused on evaluating the effectiveness of novel-teaching based on students' subjective perceptions. For this purpose, two classes of non-English majors read and received instruction on an unabridged novel for one semester. A pair of questionnaires were used to measure students' perceptions and attitudes prior to and after the novel class. Analysis of the pretest and post-test shows that after a semester-long novel-reading process, students demonstrated improvement in attitudes, confidence, interest, and their own perceived reading ability. The results are of pedagogical significance to EFL teaching in that they present how well a novel was received in an EFL class, the benefits it offered as well as the difficulties it entailed to the reading process.
\end{abstract}

Keywords: novel, main material, novel-reading, college EFL reading

\section{Introduction}

One major goal of the college EFL reading courses is to cultivate reading autonomy in the students. Such autonomy is developed through not only sufficient reading proficiency but also sustained reading interest and adequate knowledge of reading resources (Tsai, 2007). Since most EFL learners have their primary contact with the target language in the classroom, what is introduced in the class decides for the most part what they may utilize in the out-of-class context. It is thus important to "empower foreign language students to make effective use of the potential language-learning materials that exist around them" (Ryan, 1997, p. 215), to help find out prospectively motivating resources that the students can use when the EFL courses end.

Among the varied materials for reading, newspapers, magazines, and books are often brought into the instruction in many ESL/EFL programs (Cuban, 2001; Day \& Bamford, 1998). Courses involving extensive reading or literature-based instruction mostly feature graded readers and young adult literature (Day \& Bamford, 1998; Paran, 2008). In Taiwan, language learning magazines and bilingual newspapers are also common supplementary or outside reading materials (Tsai, 2007). Authentic book-length novels, however, despite their popularity in the recommended material list for pleasure reading, are rarely used to supplement textbooks, much less being central to the regular EFL curriculum.

Although researchers have suggested various benefits of introducing authentic novels in the language classrooms (Gareis, Allard, \& Saindon, 2009; Hişmanoğlu, 2005; Lazar, 1990; Vandrick, 1997), using an original, unabridged novel as the primary course material may seem "too radical a leap from tradition" (Gareis et al., 2009, p. 145). The fact that a novel does not lay out curricular items in a certain sequence as a textbook does may be regarded a drawback by the teacher; its long text and large amount of new vocabulary can be daunting to students who are used to shorter passages in traditional textbooks (Gareis et al., 2009; Lazar, 1990). Therefore, a novel is considered best for readers of high-intermediate to advanced levels of English to truly enjoy the reading experience (Gareis et al., 2009; Hişmanoğlu, 2005). Nevertheless, as Tsou (2007) observes, reading novels for pleasure is teachable even with students of lower levels of reading proficiency. With careful selection of the right works and proper guidance, the obstacles can be minimized to make novels a pleasant alternative to textbooks (Brunes, 2009; Gareis et al., 2009; Jou, 2006).

This study, based on the notion that novels present an authentically valuable source of reading for EFL students, looked into the possibility of using a novel as the main course material in a college reading course. It focused on 
evaluating the effectiveness of novel-teaching in terms of students' subjective perceptions instead of their objective linguistic gains. The research questions include:

1) Are there changes in the students' attitudes toward novel-reading and in their perceptions of using a novel as textbook after the entire reading experience?

2) What are the students' perceived gains and obstacles from reading the novel?

3) What are the strengths and weaknesses of the novel-reading class as perceived by the students?

\section{Literature Reviews}

\subsection{Novels as EFL Reading Material}

In the ELT literature, novels are often adopted in programs involving extensive reading, pleasure reading, literature circle (Chiang, 2007; Kim, 2004), literary responses (Liaw, 2001), or used to explore the reading and writing connection (Wu, 2005). In these non-literature oriented programs, novels usually take on the role of supplementary material. Gareis et al. (2009) and Melon (1994), however, advocate using novels as textbooks. Although novels do not include elements frequently present in traditional textbooks, such as vocabulary list, grammar charts, writing exercises, and pictures, they possess both the authenticity and appeal missing in a textbook. They are unedited, unabridged, natural in speech and writing, and written to communicate meaning. The imagination, fanciful possibilities, intriguing plots, and real-world language contribute to the engagement of the reader and appeal to a mass readership (Gareis et al., 2009, p. 145). The novels' lack of organized and systematical presentation of curricular items may require extra effort for course planning, but it is such quality that gives the language classroom a different atmosphere. When using a novel in the class, the teacher assumes the role as a narrator and facilitator rather than a lecturer; the students are no longer passive language learners but active readers of authentic texts that provide them a genuine perspective of the real world.

\subsection{Reasons for Using Novels in the Language Classroom}

According to Alkire (2010), Gareis et al. (2009), Hişmanoğlu (2005), Lazar (1990), Melon (1994), and Uyemura (2006), novels, with their unique characteristics as reading material, benefit the students in the following chief aspects:

1) Motivation: Novels, by addressing to complex situations, life dilemmas, and other universal themes that the readers can relate to, intrigue the readers to read on for meaning and pay less attention to form. As the readers experience the joy and satisfaction from reading the novels, they are motivated to read further. With intrinsic motivation gradually sprouted in them, they feel less anxious about the language and more pleasure from the reading process. Having successfully read the whole novel brings forth a satisfying sense of achievement, which may not otherwise be felt after reading a textbook or other short text. Such positive experience then acts as a stimulus to pick up other books for the purpose of pleasure.

2) Language improvement: As extensive reading contributes to vocabulary acquisition, reading unabridged novels also provides authentic, large exposure to the target language and therefore can be a very effective way to build vocabulary (Pellicer-Sánchez \& Schmitt, 2010) and develop reading comprehension skills (Wu, 2005). In addition, during novel reading, students become familiar with various linguistic forms, communicative functions and meanings that are intended for native speakers. The content form a basis for further writing (e.g. reading $\log$ ) and speaking (e.g. literature circle, role-play) practices. In cases where audio CDs or film adaptations of the novels are available, listening practices can also be the added value.

3) Cultural awareness: Literary texts such as novels and plays serve as a window to the target culture, showing ESL/EFL learners how native speakers think, communicate, and live. Despite an imaginary one, the world created in a novel not only reflects the author's own culture, it also presents a complete cultural setting in which characters interact and actions take place. By reading a novel, the readers obtain virtual access to the culture and discover the ways the characters view the world, and hence the learning of not only the language, but also the historical, social, political, and economical facts that shape the cultural background of the novel.

Adding to the above benefits are Maley's (1989) proposed reasons for using literature (novels being one major genre) in a language classroom: universality, non-triviality, personal relevance, variety, interest, economy and suggestive power, and ambiguity. Other advantages are that novels contribute to students' personal growth, improve critical thinking skills (Hişmanoğlu, 2005), foster student-centered learning, and give students a different reading experience from textbooks (Gareis et al., 2009). Content continuity, suggested by Melon (1994), is also one virtue of a book-length novel to be used over several weeks of lessons. 


\subsection{Research on EFL Students' Novel Reading}

Gareis et al. (2009) assert that novels can fit in diverse language programs in secondary and postsecondary education. In Hong Kong, Yang (2001) adopted a comparison study to investigate the effects of using mystery novels on non-academic adult English learners' reading proficiency and motivation. In Lebanon, Bacha (2010) explored college students' attitudes toward and preferences for novel-reading via a survey method. Both studies confirmed the benefits of novel-reading. In Spain, Pellicer-Sánchez and Schmitt (2010) chronicled vocabulary development and attitudes of $20 \mathrm{EFL}$ university students from reading an authentic novel. The results indicate the occurrence of not only substantial learning of words but also participants' positive attitudes to the novel-reading experience.

In the EFL context of Taiwan, only a few studies are found to have explored the possibility and effectiveness of teaching unabridged novels in the language classroom. Tsou (2007) used a novel as a supplementary material to the regular EFL textbook in three senior high school classes and studied the gains in the students' reading proficiency and attitudes. Other researchers examined the effects of applying novel-reading in extensive reading programs, literature-based instruction, or web-enhanced class with English majors (Wu, 2005; Jou, 2006). Although all the above-mentioned studies yielded positive results, little was known about how non-English major college students, who mostly participated in studies involving graded readers or simplified novels (Chen, 2005), reacted to and perceived the use of a novel as main course material. These students of non-advanced English proficiency presented a population worth probing into concerning authentic novel reading in the EFL classes.

\section{Method}

\subsection{Settings and Participants}

This study was conducted in two classes of the English Reading course offered at a technology university in central Taiwan. The course constitutes 18 weeks (one semester) of 2-hour sessions and has a general goal to enhance students' reading ability. There is no set curricular plan for the course and therefore no set course material is designated. The two classes consisted of 93 female nursing juniors in total, and the majority of them were considered to be of intermediate reading proficiency.

\subsection{Course Material}

An unabridged junior novelization, Night at the Museum (Goldman, 2007), was chosen to be the main course material based on criteria proposed in the ELT literatures. First of all, Day and Bamford (1998) suggest that carefully selected popular and simple literature, along with young adult literature, are among those reading material suitable for intermediate students. The novel is 12-chapter and 137-page long, an ideal length to be covered in a semester when extra activities are included (Melon, 1994). Its content is short comparing to other unabridged novels; the language level is sufficiently challenging but not demotivating. The pre-set chapters clearly and conveniently divide the whole text into manageable pedagogic units that can be comfortably integrated in the amount of time available per week (Lazar, 1990). The novel is set in a world-class museum existing in reality in contemporary New York City and has weaved in many famous historical figures and events. This offers students a chance to gain not only insight into the contemporary US culture but also knowledge about world history and geography (Uyemura, 2006). The language is up-to-date and straightforward and involves more action than description (Melon, 1994). In fact, the novel contains a lot of dialogues identical to the script of its 2006 film version of the same title.

To ease students into the reading process, Lazar (1990) suggests that a list of words likely to be of difficulty or puzzlement be prepared with dictionary entries in advance. She cautions that even advanced readers would become discouraged from having to frequently stop to look up new words. In this course, the teacher prepared a list of words, phrases, and sentences that are of confusing definitions or colloquial uses from each chapter for students to refer to during their previews. In addition, another list of people, places, events, and objects mentioned in the novel (Items of Interest) was also passed out for information-gathering and information-sharing activities. This was meant for students to extend their reading to subjects related to the novel's cultural background.

\subsection{Course Design}

According to Paran (2008), a course incorporating both literature and language learning would, determined by its focus, fall into either one of the four quadrants formed by two intersecting lines of literature and language teaching. The novel course involved in this study, with neither focus on literary qualities of the novel nor focus on explicit language learning work, falls in the quadrant exemplifying extensive reading. 
At the outset of the reading class, quick facts about the course book were given. Students were told to read one or two chapters each week in order to finish reading the entire novel by the end of the semester. They were also encouraged to read extensively, instead of reading word by word. Before each chapter was gone over in the class, a quiz of 5 multiple choice questions was given to test students' comprehension of the content and at the same time to check if proper preview had been done. Throughout the semester, 11 quizzes and 4 review tests that consisted of mainly comprehension questions were given. Students were divided into groups. Each group was responsible for sharing five Items of Interest with the class using PowerPoint slides.

As is proposed by Alkire (2010) and others (Chen, 2005; Gareis et al., 2009; Melon, 1994; Premawardhena, 2007), a well-known visual counterpart of a novel can aid novel-teaching in a motivating and effective way. Familiarity with the film lessens the difficulty level of the text as well as students' anxiety to comprehend the novel. The students in this study were encouraged to watch the 2006 film of the same title outside of class. When time permitted, the section of the film corresponding to the chapter under discussion was also shown in class to merit discussions about the differences between the novel and the film.

\subsection{Instrument}

A pair of novel-reading questionnaires were designed with reference to Bacha (2010) and Chiang (2007) to measure students' perceptions prior to and after the novel-reading experience in the Advance English Reading course. Both questionnaires consisted of 23 similar Likert 5 -scale items pertaining to measure students' perceptional changes in terms of their attitudes toward novel-reading ( 8 items), their confidence in novel-reading (5 items), and the appropriateness of using a novel as textbook (10 items).

Besides Likert items, the pre-reading questionnaire (pretest) incorporated questions about students' demographical information and their previous reading experiences. The post-reading one (post-test) included questions about students' novel-reading experiences as well as open-ended questions eliciting their opinions about the course. Both questionnaires had undergone expert examinations and pilot tests for validity, and achieved relatively high reliability Cronbach's Alpha $(\operatorname{Pre}=.910$; Post $=.917)$.

\subsection{Data Collection and Analysis}

The pretest and the post-test were given respectively when the class met for the first ( $1^{\text {st }}$ week) and the last time $\left(18^{\text {th }}\right.$ week $)$ during the semester. Before pre- and post-survey administration, students were ensured that their responses to the questionnaires would not by any means influence their course grades.

Pre- and post-test results were analyzed to gain better understanding of the students' reading experiences and to discover statistically significant differences in their perceptions toward novel-reading prior to and after the reading process. To serve this purpose, frequency and percentage techniques were applied to analyze the multiple choice questions on students' pre-reading and post-reading experiences. Paired-samples t-test was calculated to compare the means of the pre-test and post-test scores gained in the 23 Likert items. Responses given to the four open-ended questions in the post-test were analyzed through coding and frequency calculation.

\section{Results}

\subsection{Overall Perceptions of Novel-reading}

Background information collected via the pretest revealed that the students had very little previous novel-reading experience. Only one-third of the 93 students had read simplified novels and a mere three had experiences of leafing through a few pages of original ones. After a semester's novel class, the post-test revealed that for most of the students, the novel's difficulty level was either "just right" (49.5\%) or "difficult but manageable" (46.3\%), and the scheduled progress of novel reading was "just right" (77.4\%). Only one out of the 93 students thought the novel was "too difficult" and the progress "too fast." A mean of 4.03 was obtained from students' self-evaluation of their effort put in novel reading on a 1 (little) to 5 (very much) scale.

Analysis of the Likert items in the pretest and post-test indicates that there were significantly positive changes in students' overall perceptions of novel-reading $(\mathrm{t}=-6.17, p<.001)$ after a semester-long reading process. As shown in Table 1, the significant gains in posttest scores result in very small $\mathrm{p}$ values, suggesting that the novel-reading experience had succeeded in causing positive changes in students' attitudes $(\mathrm{t}=-6.58, p<.001)$ toward and their confidence $(\mathrm{t}=-2.22, p=.029)$ in reading novels. They also held a firmer belief that novels can be used as main material for the reading course $(\mathrm{t}=-5.93, p<.001)$. 
Table 1. Paired Samples Test of Students' Perceptions of Novel-reading

\begin{tabular}{|c|c|c|c|c|}
\hline & \multicolumn{3}{|c|}{ PRE - POST } & \multirow[b]{2}{*}{ Sig. (2-tailed) } \\
\hline & Mean & SD & & \\
\hline Attitudes towards novel-reading & -3.02 & 4.41 & -6.58 & $.000 * * *$ \\
\hline Confidence in novel-reading & -.77 & 3.23 & -2.22 & $.029 *$ \\
\hline Perceptions of using a novel as textbook & -3.78 & 5.99 & -5.93 & $.000 * * *$ \\
\hline Overall & -7.53 & 11.12 & -6.17 & $.000 * * *$ \\
\hline
\end{tabular}

Note. $*: \mathrm{p}<.05, * * *: \mathrm{p}<.001$

A detailed look into each item provides clearer and somewhat different views. As can be seen from Table 2 , items categorized under "Attitudes toward novel-reading" generally receive above-average mean scores in pretest, indicating little attitudinal resistance to reading a novel at the outset of the course. At the end of the semester, students liked reading in English better $(\mathrm{t}=-4.96, p<.001)$; they also liked the novel more $(\mathrm{t}=-5.63$, $p<.001)$ and felt happier to finish reading it than they had previously expected $(\mathrm{t}=-5.24, p<.001)$. Most impressively, students' anxiety level experienced with novel reading went down an average of a full point on the scale $((\mathrm{t}=-8.50, p<.001$; reversely coded $)$, suggesting that as the reading process rolled on, the anxiety accompanying it was diminishing. However, Table 3 shows that despite a rise in the students' confidence in their ability to read a novel on their own $(\mathrm{t}=-3.08, p=.003)$, they still doubted about such ability, especially without the aid of a dictionary. This was perhaps due to the difficulty they experienced during the novel-reading process.

Table 2. Paired Samples Test of Students' Attitudes Toward Novel-reading

\begin{tabular}{|c|c|c|c|c|c|c|c|c|}
\hline \multirow[t]{2}{*}{ Item statement (Posttest) } & \multicolumn{2}{|l|}{ Pretest } & \multicolumn{2}{|c|}{ Posttest } & \multicolumn{2}{|c|}{ Paired Differences } & \multirow[b]{2}{*}{$\mathrm{t}$} & \multirow{2}{*}{$\begin{array}{l}\text { Sig. } \\
\text { (2-tailed) }\end{array}$} \\
\hline & Mean & $\mathrm{SD}$ & Mean & SD & Mean & SD & & \\
\hline I like reading in English. & 3.16 & .88 & 3.62 & 1.02 & -.46 & .88 & -4.96 & $.000 * * *$ \\
\hline $\begin{array}{l}\text { I like reading materials that are } \\
\text { challenging for my level. }\end{array}$ & 3.20 & .98 & 3.33 & 1.01 & -.13 & .90 & -1.38 & .170 \\
\hline $\begin{array}{l}\text { It makes me happy to finish } \\
\text { reading an English novel. }\end{array}$ & 4.23 & .77 & 4.72 & .54 & -.49 & .90 & -5.24 & $.000 * * *$ \\
\hline I enjoy the novel-reading class. & 3.79 & .76 & 3.96 & .81 & -.16 & .88 & -1.78 & .079 \\
\hline $\begin{array}{l}\text { I feel anxious about the } \\
\text { novel-reading class. }\end{array}$ & 3.01 & 1.19 & 4.08 & .87 & -1.07 & 1.20 & -8.50 & $.000 * * *$ \\
\hline $\begin{array}{l}\text { I like the novel used in this } \\
\text { reading class. }\end{array}$ & 3.83 & .75 & 4.36 & .74 & -.53 & .91 & -5.63 & $.000 * * *$ \\
\hline $\begin{array}{l}\text { I read the novel mainly for } \\
\text { pleasure. }\end{array}$ & 3.61 & .88 & 3.75 & .90 & -.14 & .88 & -1.53 & .129 \\
\hline $\begin{array}{l}\text { I will try to read another novel } \\
\text { after this course ends. }\end{array}$ & 3.51 & .87 & 3.55 & .92 & -.04 & 1.10 & -.38 & .705 \\
\hline
\end{tabular}

Note. $* * *: \mathrm{p}<.001$

Table 3. Paired Samples Test of Students' Confidence in Novel-reading Ability

\begin{tabular}{|c|c|c|c|c|c|c|c|c|}
\hline \multirow[t]{2}{*}{ Item statement (Posttest) } & \multicolumn{2}{|l|}{ Pretest } & \multicolumn{2}{|c|}{ Posttest } & \multicolumn{2}{|c|}{ Paired Differences } & \multirow[b]{2}{*}{$\mathrm{t}$} & \multirow{2}{*}{$\begin{array}{l}\text { Sig. } \\
\text { (2-tailed) }\end{array}$} \\
\hline & Mean & SD & Mean & SD & Mean & SD & & \\
\hline $\begin{array}{l}\text { I have little difficulty reading } \\
\text { the novel. }\end{array}$ & 2.80 & .88 & 2.89 & 1.10 & -.09 & 1.11 & -.76 & .449 \\
\hline $\begin{array}{l}\text { I can read the novel according } \\
\text { to the progress of the class. }\end{array}$ & 3.77 & .73 & 3.77 & .79 & .00 & .94 & .00 & 1.000 \\
\hline $\begin{array}{l}\text { I can read the novel all by } \\
\text { myself. }\end{array}$ & 2.42 & .89 & 2.80 & 1.10 & -.38 & 1.19 & -3.08 & $.003 * *$ \\
\hline $\begin{array}{l}\text { I cannot read the novel without } \\
\text { the teacher's instruction. }\end{array}$ & 3.07 & 1.05 & 3.18 & 1.17 & -.11 & 1.28 & -.82 & .414 \\
\hline $\begin{array}{l}\text { I cannot read the novel without } \\
\text { a dictionary. }\end{array}$ & 2.33 & .90 & 2.45 & 1.06 & -.12 & 1.15 & -1.00 & .320 \\
\hline
\end{tabular}

Note. $* *: p<.01$ 
Students' perceptions of using a novel as the main course material, as displayed in Table 4, were also generally positive before the actual use of one in the class. After a semester's reading and discussions on the novel, students showed substantial gains in their beliefs that novel is suitable material for reading course $(\mathrm{t}=-3.04, p$ $=.003)$ and that it benefited students in terms of interest in English $(\mathrm{t}=-4.18, p<.001)$, reading motivation $(\mathrm{t}=$ $-4.50, p<.001)$, and affect $(\mathrm{t}=-4.02, p<.001$; "frustration" reversely coded). Interest enhancement, in particular, is the most acknowledged effect of a novel, receiving a high 4.35 on average. The possibility of frustration, although significantly lessened, was nevertheless still present. Again, difficulty of the novel might have caused such frustration. When compared with regular textbooks, novels secured stronger support from the beginning to the end. At the posttest, students expressed a significantly firmer agreement that novels exceeded regular textbooks in terms of suitability $(\mathrm{t}=-4.43, p<.001)$ and its ability to enhance proficiency $(\mathrm{t}=-3.68, p<.001)$, interest $(\mathrm{t}=-3.62, p<.001)$, motivation $(\mathrm{t}=-4.22, p<.001)$, and cause of lower level of frustration $(\mathrm{t}=-6.22, p$ $<.001)$.

Table 4. Paired Samples Test of Students' Perceptions of Using a Novel as Textbook

\begin{tabular}{|c|c|c|c|c|c|c|c|c|}
\hline \multirow{2}{*}{$\begin{array}{l}\text { Item statement } \\
\text { (Posttest) }\end{array}$} & \multicolumn{2}{|l|}{ Pretest } & \multicolumn{2}{|c|}{ Posttest } & \multicolumn{2}{|c|}{ Paired Differences } & \multirow[b]{2}{*}{$\mathrm{t}$} & \multirow{2}{*}{$\begin{array}{l}\text { Sig. } \\
\text { (2-tailed) }\end{array}$} \\
\hline & Mean & SD & Mean & SD & Mean & SD & & \\
\hline $\begin{array}{l}\text { A novel is suitable to be used as the } \\
\text { main material in a reading course. }\end{array}$ & 3.89 & .74 & 4.21 & .74 & -.32 & 1.00 & -3.04 & $.003 * *$ \\
\hline $\begin{array}{l}\text { A novel is more suitable to be used } \\
\text { as an outside material than as the } \\
\text { main material. }\end{array}$ & 3.43 & .87 & 3.89 & .72 & -.46 & .99 & -4.43 & $.000 * * *$ \\
\hline $\begin{array}{l}\text { Using a novel as the main material } \\
\text { helps improve my English. }\end{array}$ & 4.14 & .55 & 4.21 & .70 & -.07 & .80 & -.79 & .434 \\
\hline $\begin{array}{l}\text { A novel helps more than a regular } \\
\text { reading textbook in improving my } \\
\text { English. }\end{array}$ & 3.84 & .73 & 4.18 & .63 & -.35 & .91 & -3.68 & $.000 * * *$ \\
\hline $\begin{array}{l}\text { Using a novel as the main material } \\
\text { helps increase my interest in English. }\end{array}$ & 3.98 & .65 & 4.35 & .67 & -.37 & .85 & -4.18 & $.000^{* * *}$ \\
\hline $\begin{array}{l}\text { A novel helps more than a regular } \\
\text { reading textbook in increasing my } \\
\text { interest in English. }\end{array}$ & 3.98 & .70 & 4.35 & .71 & -.37 & .99 & -3.62 & $.000 * * *$ \\
\hline $\begin{array}{l}\text { Using a novel as the main material } \\
\text { motivates me to read. }\end{array}$ & 3.82 & .73 & 4.24 & .70 & -.42 & .91 & -4.50 & $.000 * * *$ \\
\hline $\begin{array}{l}\text { The novel helps more in motivating } \\
\text { me to read than a regular reading } \\
\text { textbook does. }\end{array}$ & 3.89 & .73 & 4.29 & .70 & -.40 & .92 & -4.22 & $.000 * * *$ \\
\hline $\begin{array}{l}\text { Using a novel as the main course } \\
\text { material frustrates me. }\end{array}$ & 2.86 & .96 & 3.26 & .94 & -.41 & .97 & -4.02 & $.000 * * *$ \\
\hline $\begin{array}{l}\text { The novel frustrates me more than a } \\
\text { regular reading textbook does. }\end{array}$ & 3.15 & .95 & 3.85 & .89 & -.69 & 1.06 & -6.22 & $.000 * * *$ \\
\hline
\end{tabular}

Note. ${ }^{* *}: \mathrm{p}<.01, * * *: \mathrm{p}<.001$

\subsection{Perceived Gains and Obstacles from Novel-reading}

The four open-ended questions in the post-reading questionnaire were meant to elicit students' opinions about the novel-reading class and to answer research questions 2 and 3. Out of the 93 students, 9 left all the questions blank; 84 provided responses to the first, second, and third questions; 78 responded to the fourth. Table 5 summarizes students' responses to the first question: What have you learn most from this semester's novel-reading experience? The most mentioned gains are related to English ability (Items 1, 2, 6, and 7), knowledge (Items 3 and 4), and pleasure in reading (Item 5). 
Table 5. Frequency Counts of Students' Self-stated Gains from Novel-reading $(\mathrm{n}=84)$

\begin{tabular}{lll}
\hline Item & Gains from novel reading & Count $^{\mathrm{a}}$ \\
\hline 1 & Vocabulary and phrases & 49 \\
2 & Reading ability and novel-reading strategies & 41 \\
3 & Background culture & 38 \\
4 & Extra knowledge extended from the content & 37 \\
5 & Pleasure in reading/learning English & 29 \\
6 & Practical, everyday use of English & 17 \\
7 & Grammar/sentence structure & 13 \\
8 & Speaking, listening, and writing practices extended from the text & 6 \\
\hline
\end{tabular}

Note. ${ }^{\text {a }}$ Only items receiving more than 5 counts are shown.

The most mentioned obstacles during novel-reading were discovered via the second open-ended question: What are the main difficulties you have experienced when reading the novel? Table 6 shows that the obstacles students perceived were mostly related to linguistic aspects. As several student stated, they had to look up all the unfamiliar words in the dictionary in order to understand the content of the novel. The number of new words and the high frequency of referring to a dictionary gradually wore out their patience. Some students also complained that even when they checked up all the words, they still had a hard time comprehending the content because of their poor grammatical knowledge. For quite a few students, however, the obstacles could be attributed to psychological aspect, such as lack of patience, confidence, and interest in English or the novel itself.

Table 6. Frequency Counts of Students' Self-stated Obstacles during Novel-reading $(\mathrm{n}=84)$

\begin{tabular}{ll}
\hline Obstacles during novel-reading & Count $^{\mathrm{a}}$ \\
\hline Grammar/Sentences structures & 43 \\
Vocabulary and phrases & 38 \\
Lack of patience/Laziness & 22 \\
Lack of confidence & 14 \\
Not enough time & 7 \\
Lack of interest in English & 5 \\
Lack of interest in the novel & 5 \\
\hline
\end{tabular}

Note. ${ }^{a}$ Only items receiving more than 5 counts are shown.

\subsection{Perceived Strengths and Weaknesses of the Novel-reading Class}

Table 7 shows a summary of students' responses to the third open-ended question: What do you think are the strengths of the novel-reading class? Students stated positively that the class helped enhance reading motivation and interest in English, make reading more relaxing and less pressured; hence a special reading experience and a brand-new view about reading. The novel provided practical, everyday use of English; reading it helped learn words, phrases, and grammar in an easier and more natural way, and finishing it boosted a sense of achievement. Students specially gave positive accounts of the use of movie and PowerPoint slides in class. They affirmed the effectiveness of watching the movie in promoting text comprehension. Using PowerPoint to supply extra cultural and other facts about the world (Items of Interest in the novel) was also considered pleasurable and knowledge enriching.

Table 7. Frequency Counts of Students' Feedback on the Strengths of the Novel Class $(n=84)$

\begin{tabular}{lc}
\hline Strengths of the novel class & Count $^{\mathrm{a}}$ \\
\hline (The class) Enhances motivation to read and interest in English & 56 \\
(The use of movie) Assists in comprehending the novel & 32 \\
(The class) Makes reading a more relaxing and less pressured activity & 28 \\
(The use of PowerPoint slides) Increases understanding of American culture and provides extra & 27 \\
knowledge of historical and geographical facts about the world & 13 \\
(The use of PowerPoint slides) Adds pleasure to and enriches the class & 10 \\
(The novel) Helps learn practical, everyday use of English & 7 \\
(The novel) Helps learn words, phrases, and grammar in a more natural way & 7 \\
(The class) Offers special reading experience and a brand-new view about reading & 6 \\
\hline
\end{tabular}

Note. ${ }^{\text {a }}$ Only items receiving more than 5 counts are shown. 
The fourth open-ended question asks: What do you think are the weaknesses of the novel-reading class? Fifteen students left it blank, while a total of 58 gave "None" as an answer, indicating that $62 \%$ of all the students thought no aspect of the class needed to be adjusted. Table 8 lists the comments given by the rest 20 students. Their discontentment was mostly concerning the "hasty" nature of the instruction. They stated that oftentimes details about the content and grammatical points went unexplained because too many pages were covered in a single lesson.

Table 8. Frequency Counts of Students' Feedback on the Weaknesses of the Novel Class $(n=78)$

\begin{tabular}{ll}
\hline Weaknesses of the novel class & Count \\
\hline Not enough explanations about the content/important points. & 10 \\
Some parts were skipped in class. & 5 \\
Each test covers too much content. & 4 \\
Not enough explanations about grammar & 3 \\
Not enough practices of speaking & 1 \\
Too difficult & 1 \\
\hline
\end{tabular}

\section{Discussion}

Findings from this current study are in agreement with several earlier studies and educators who proposed to integrate literature in ESL/EFL classes. That is, using an authentic literary work benefits in increasing students' motivation and interest in reading (Gareis et al., 2009; Kim, 2004; Paran, 2008; Tsou, 2007; Wu, 2005). It has the potential not only to involve EFL students in enjoyable reading experience but also to develop their linguistic ability and cultural awareness. Although for almost all the students in this study (96.8\%), reading an original novel was an unprecedented experience, they did not fear for such a challenge. They had some doubt in their ability to handle the anticipated difficulty of reading a novel, but their attitudes were generally positive. After a semester-long novel-reading process, they demonstrated improvement not only in attitudes, confidence, and interest, but also in their own perceived reading ability.

Other than that, the study provides insight into aspects of the novel class that are considered helpful or insufficient in the viewpoints of the students, as well as difficulties students tend to encounter during novel reading. While grammar and vocabulary topped all other obstacles as two most encountered difficulties, vocabulary/phrases was ranked also as the most perceived gains from reading the novel. This implies that vocabulary is more easily to tackle with and convert from a roadblock to an asset. At the initial stage of novel reading, frequent encounters of new words may hinder the flow of reading and cause frustration. But when the reading moves on, words that repeatedly appear in the text tend to facilitate incidental or explicit vocabulary acquisition. As is indicated by several studies (Gareis et al., 2009; Hişmanoğlu, 2005; Pellicer-Sánchez \& Schmitt, 2010), through a holistic, meaning-focused reading of authentic novels, readers can pick up a significant amount of vocabulary. In this study, students' acquisition of vocabulary was never measured through testing. Quizzes and tests were given only to assess if students understood the content of the novel. Without pressure from tests, words and phrases in the novel were learned more naturally with the help of the word/phrase list prepared by the teacher and were reinforced by the audiovisual supplements such as the movie and PowerPoint slides.

Grammar, however, does not seem to be acquired through the same mechanism. Even with all words checked up, some sentences can still be hardly comprehensible due to their syntactic complexity. This results in less effective grammar acquisition, as also pointed out by Tsou's (2007). Such problem posed to be what troubled students the most but unfortunately received insufficient attention in the novel course. For some students in the study, grammar knowledge might be more effectively obtained through teacher's explicit explanations than students' probing their own way through those syntactic structures. Owing to limited course hours, most of the class instruction and activities focused on familiarizing students with the plot. Grammatical points were only sporadically mentioned. This might have resulted in students' doubt about what substantial language skills they had learned. Although novel reading is by nature a form of extensive reading which focuses on meaning rather than form (Tsou, 2007), Lazar (1990) cautions that many language learners are skeptical about using a novel in the classroom because it may somehow detract from what they perceive they need to learn, such as grammar learning. In this regard, how to justify the use of the novel to students; namely, how to utilize the novel as material for extensive reading and at the same time exploit it as a source of language learning that conforms more closely to students' expectations is an important issue to consider during course planning. 
As for what constituted the novel course, the multimedia supplements such as the film on the work, PowerPoint slides, and online texts received very positive feedback. Paran (2008) observes that having technologies incorporated into teaching is now almost commonplace. Where literature and technology are integrated in a language curriculum, with either teachers themselves utilizing film, PowerPoint, and web and its resources, or students being required to access the Internet themselves, the effects are usually a fruitful one. Students in this study mentioned that these supplementary materials helped familiarize them with not only the plot of the story, language use in the novel, but also cultural and other useful knowledge extended from the reading. The latter benefits upgrade reading to a level where it is not just a skill of language, but a means to learn about the world.

Most encouraging of all was students' unwavering support to using the novel as the main course material in the reading class. They welcomed the use of novel from the outset, which resonates with Wu's (2005) discovery that students tend to give warm greetings to "anything other than a conventional textbook" (p. 66) and that the use of novel is helpful in arousing students' motivation to read at the initial stage. The fact is that after years of using textbook-format types of books in their past EFL classes, students would opt for a change. Such a change may result in ambiguous attitudes - mixed feelings of excitement and doubt. Whether it is a change for the better or for the worse relies heavily on the selection of the alternative material and the teaching methods involved in the process.

\section{Conclusions}

The novel used in this study proved to be a favorable choice because it successfully catered to the students' interest in the first place. It closely matches its movie version, which is popular among Taiwanese audiences. The entertaining feature of movie-watching more or less brought forth pleasure to novel-reading and counteracted the anxiety provoked by the text. Nevertheless, interest alone is not enough to sustain reading motivation from the beginning to the end, especially when the novel's linguistic complexity is above students' current proficiency level. For some of the students in this study, the novel used was considered to be somewhat beyond comprehension. A novel of this level of difficulty may not suit the purpose of pleasure reading. However, this is exactly why it is suitable to serve instead as a course material, before students of intermediate proficiency are ready to venture into reading a novel on their own. Vandrick (1997) asserts that "Reading fiction is a process to which students need to be oriented." This is especially true with novice novel readers. With a supportive context constructed, students will not feel overwhelmed by the authentic novel (Uyemura, 2006). Teachers may assume the role of a coach and a cheerleader that helps make the reading process less intimidating with their clear guidance, scaffolding, and encouragement (Paran, 2008; Vandrick, 1997). They are to pave way for students' future pleasure reading in English by providing them with a chance to finish a novel and feel the sense of accomplishment. Through carefully planned class instruction, students acquire adequate novel-reading strategies and confidence that can be applied to their future independent reading. When they are able to pick up a novel and manage to comprehend it with little problem, the joy of reading will emerge, and hence the virtuous circle of an autonomous reader.

The study is experimental and pioneer in the sense that little empirical studies have been found to explore the feasibility of using an authentic novel as the textbook with intermediate-level, non-English-major students. Although the data collected from students' self reports are subjective in nature, the results will be of pedagogical significance to EFL teaching and learning in that they present how well a novel was received in an EFL class, the benefits it offered as well as the difficulties it entailed to the reading process. Further research may probe into substantial evidence of students' linguistic gains from novel-reading. Qualitative methods are also suggested to look into students' strategic use and attitudinal changes during the process.

\section{References}

Alkire, S. (2010). Teaching novels in EFL/ESL classes. The English-Learning and Languages Review. Retrieved from http://www.lingua.org.uk/novteach.alkire.html

Bacha, N. N. (2010). Teaching literature in an English as a foreign language classroom: A study of student attitudes. The International Journal of the Humanities, 8(1), 47-64.

Chen, L. J. (2005). Blending video films with novels to enhance EFL college students' English communicative competence: From the view of cognitive learning and communicative language teaching. Journal of Cheng Shiu University, 18, 229-242.

Chiang, M. H. (2007). Improved reading attitudes and enhanced English reading comprehension via literature circles. Lagos Papers in English Studies, 1, 168-183.

Cuban, S. (2001). Reading for pleasure. Focus on Basics, 5(A), 20-23. 
Day, R. R., \& Bamford, J. (1998). Extensive reading in the second language classroom. Cambridg UK: Cambridge University Press. http://dx.doi.org/10.1177/003368829802900211

Gareis, E., Allard, M., \& Saindon, J. (2009). The novel as textbook. TESL Canada Journal, 26(2), 136-147.

Goldman, L. (2007). Night at the Museum. New York: Barron's.

Hişmanoğlu, M. (2005). Teaching English through literature. Journal of Language and Linguistic studies, 1(1), 53-65.

Jou, Y. J. (2006). Energizing the novel teaching through computer-assisted instruction. Cheng Shiu General Education Journal, 3, 67-86.

Kim, M. (2004). Literature discussions in adult L2 learning. Language and Education, 18(2), 145-166. http://dx.doi.org/10.1080/09500780408666872

Krashen, S. (2006). Stephen Krashen: Pleasure reading. Young Learners Sig. Retrieved from http://www.iatefl.hu/docs/Stephen_Krashen.pdf

Lazar, G. (1990). Using novels in the language-learning classroom. ELT Journal, 44(3), 204-214. http://dx.doi.org/10.1093/elt/44.3.204

Liaw, M. L. (2001). Exploring literary responses in an EFL classroom. Foreign Language Annals, 34(1), 35-44. http://dx.doi.org/10.1111/j.1944-9720.2001.tb02800.x

Maley, A. (1989). Down from the pedestal: Literature as resource. In R. Cater, R. Walker, \& C. J. Brumfit (Eds.), Literature and the learner: Methodological approaches (pp. 10-24). Basingstoke, London: Modern English Publications.

Melon, C. F. (1994). Reading for pleasure: Short novels in academic university ESL programs. Journal of the Imagination in Language Learning, 2. Retrieved from http://www.njcu.edu/cill/vol2/meloni.html

Paran, A. (2008). The role of literature in instructed foreign language learning and teaching: An evidence-based survey. Language Teaching, 41(4), 465-496. http://dx.doi.org/10.1017/S026144480800520X

Pellicer-Sánchez, A., \& Schmitt N. (2010). Incidental vocabulary acquisition from an authentic novel: Do Things Fall Apart? Reading in a Foreign Language, 22(1), 31-55.

Premawardhena, N. C. (2007). Integrating literature into foreign language teaching: A Sri Lankan perspective. Novitas-ROYAL, 1(2), 92-97.

Tsai, C. H. (2007). Taiwanese college EFL students'self-directed reading in out-of-class contexts. Taipei: Crane.

Tsou, W. J. (2007). An approach to teaching the English novel to high school students in Taiwan: Its corrections with English reading ability and the students' attitudes to novel reading and teaching. Master's thesis, National Chengchi University, Taipei, Taiwan. Retrieved from http://nccur.lib.nccu.edu.tw/bitstream/140.119/33450/1/51006201.pdf

Uyemura, E. (2006). Some novel ideas: Using authentic novels in community college ESL classes. Proceedings of the CATESOL State Conference. Retrieved from http://www.catesol.org/06Uyemura.pdf

Vandrick, S. (1997). Reading responding to novels in the university ESL classroom. Journal of the Imagination in Language Learning, 4. http://dx.doi.org/10.2307/3587980

Wu, M. L. (2005). Read to enjoy: A case study using popular fiction in an EFL class. Master's thesis, Tamkang University, Taipei, Taiwan. Retrieved from http://tkuir.lib.tku.edu.tw:8080/dspace/handle/987654321/30018

Yang, A. (2001). Reading and the non-academic learner: A mystery solved. System, 29, 451-466. http://dx.doi.org/10.1016/S0346-251X(01)00038-0 